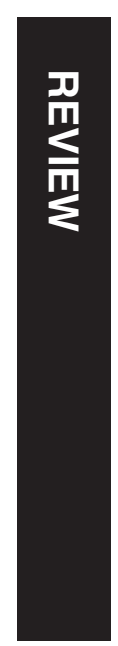

${ }^{1}$ The Stephen A. Wynn Institute for Vision Research, The University of lowa, lowa City, IA, USA

${ }^{2}$ Department of

Ophthalmology and Visual Sciences, The University of lowa, lowa City, IA, USA

Correspondence: RF Mullins, Department of Ophthalmology and Visual Sciences, The University of lowa, The Stephen A. Wynn Institute for Vision Research, 4130 MERF, 375 Newton Road, lowa City, IA 52242, USA

Tel: +319 335 8222;

Fax: +3193356641.

E-mail: robert-mullins@

uiowa.edu

Received: 4 August 2016 Accepted in revised form: 6 September 2016

Published online:

7 October 2016

\section{Structural and molecular changes in the aging choroid: implications for age-related macular degeneration}

\author{
Abstract \\ Age-related macular degeneration (AMD) is \\ a devastating disease-causing vision loss in \\ millions of people around the world. In \\ advanced stages of disease, death of photo- \\ receptor cells, retinal pigment epithelial \\ cells, and choroidal endothelial cells (CECs) \\ are common. Loss of endothelial cells of the \\ choriocapillaris is one of the earliest detect- \\ able events in AMD, and, because the outer \\ retina relies on the choriocapillaris for \\ metabolic support, this loss may be the \\ trigger for progression to more advanced \\ stages. Here we highlight evidence for loss \\ of CECs, including changes to vascular \\ density within the choriocapillaris, altered \\ abundance of CEC markers, and changes to \\ overall thickness of the choroid. Further- \\ more, we review the key components and \\ functions of the choroid, as well as Bruch's \\ membrane, both of which are vital for \\ healthy vision. We discuss changes to the \\ structure and molecular composition of these \\ tissues, many of which develop with age and \\ may contribute to AMD pathogenesis. For \\ example, a crucial event that occurs in the \\ aging choriocapillaris is accumulation of the \\ membrane attack complex, which may result in \\ complement-mediated CEC lysis, and may be a \\ primary cause for AMD-associated choriocapil- \\ laris degeneration. The actions of elevated \\ monomeric C-reactive protein in the chorioca- \\ pillaris in at-risk individuals may also contribute \\ to the inflammatory environment in the choroid \\ and promote disease progression. Finally, we \\ discuss the progress that has been made in the \\ development of AMD therapies, with a focus on \\ cell replacement. \\ Eye (2017) 31, 10-25; doi:10.1038/eye.2016.216; \\ published online 7 October 2016 \\ Introduction to age-related macular
degeneration \\ Age-related macular degeneration (AMD) is a \\ major cause of irreversible vision loss in people \\ over the age of 60 in developed countries. ${ }^{1}$ It has \\ been estimated that at least 1 in 10 Caucasian \\ Americans over the age of 80 are living with \\ AMD. ${ }^{1}$ The prevalence of AMD worldwide has \\ been estimated at $8.69 \%$, with prevalence at \\ $12.3 \%$ for those of European ancestry. When \\ divided into early and late AMD groups, global \\ prevalence is $8.01 \%$ and $0.37 \%$, respectively. ${ }^{2}$ \\ Whereas the manifestations of AMD are \\ varied, the two primary forms are dry (atrophic; \\ non-exudative) and wet (neovascular; \\ exudative) AMD. Early dry AMD is \\ characterized clinically by pigmentary changes \\ and/or drusen formation within the macula, \\ which consists of the central-most $6 \mathrm{~mm}$ of the \\ retina. With advanced dry AMD, patients can \\ develop regions of geographic atrophy (GA), in \\ which photoreceptor cell, retinal pigment \\ epithelial (RPE) cell, and choroidal endothelial \\ cell (CEC) loss are visible upon fundoscopic \\ examination. Neovascular or wet AMD patients \\ develop aberrant subretinal or sub-RPE \\ choroidal vessels that often lead to leakage of \\ blood, fluid, and/or exudates into the macula \\ (commonly referred to as a choroidal \\ neovascular membrane; CNVM). A GA lesion or \\ CNVM corresponds to scotoma in the patient's \\ central visual field. Whereas this scotoma is \\ currently permanent in the case of GA, patients \\ with CNVM may regain some vision after anti- \\ VEGF therapy. ${ }^{3}$ \\ Photoreceptor cells, RPE cells, Bruch's \\ membrane (BrM), and choriocapillaris are \\ interdependent layers of the outer retina or
}

KR Chirco ${ }^{1,2}$, EH Sohn 1,2, EM Stone ${ }^{1,2}$, BA Tucker ${ }^{1,2}$ and RF Mullins ${ }^{1,2}$ 

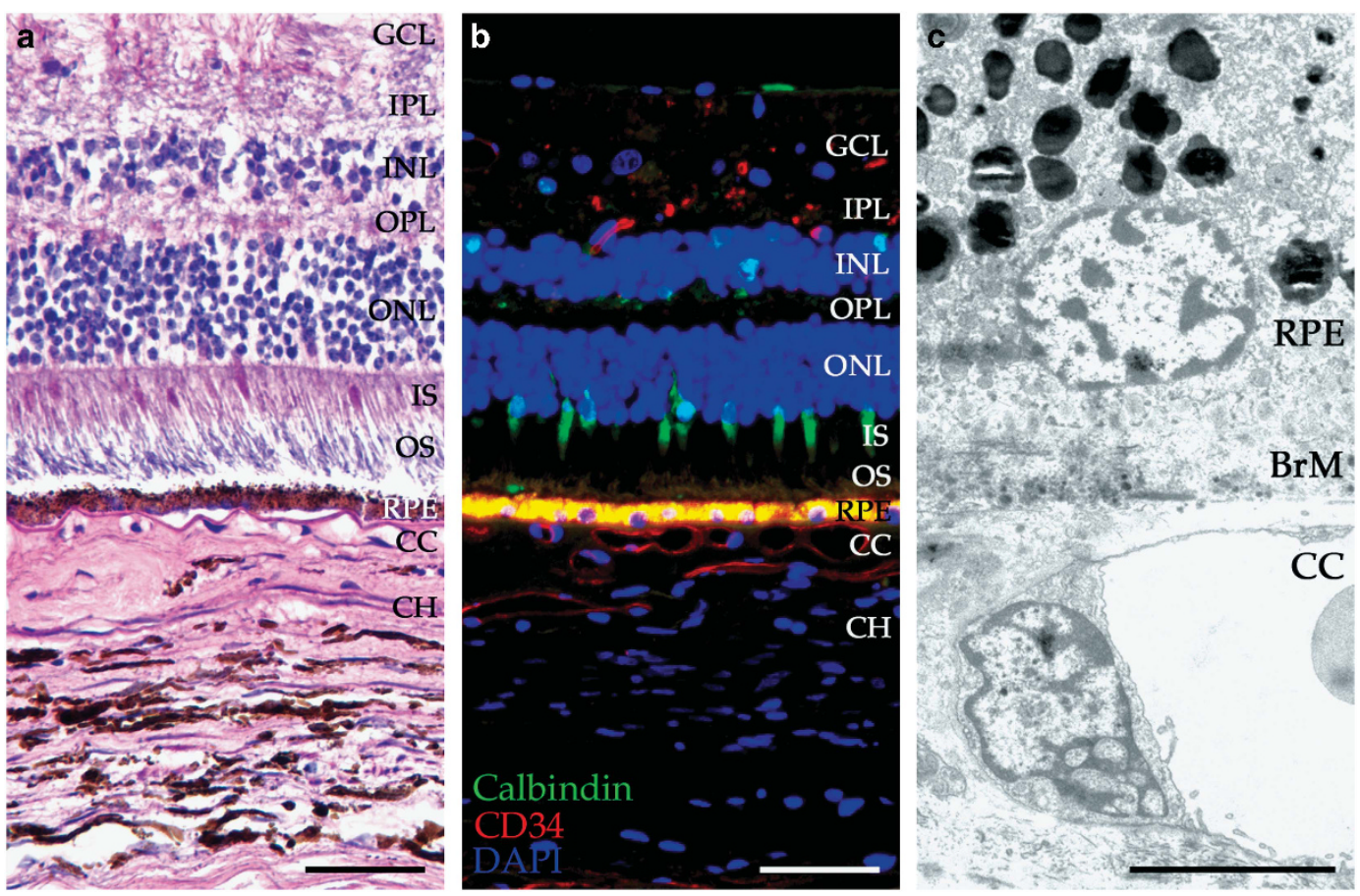

Figure 1 Layers of the neural retina, RPE, and choroid. H\&E (a), immunofluorescence (b), and TEM (c) images showing the layers of the neural retina (cones labeled with calbindin in green), retinal pigment epithelium (yellow), and choroid (vessels labeled with CD34 in red). (b) Immunofluorescence was carried out using anti-calbindin (green) and anti-CD34 (red) antibodies to visualize cone photoreceptor cells and endothelial cells, respectively. Section was counterstained with 4',6-diamidino-2-phenylindole (DAPI; blue). GCL, ganglion cell layer; IPL, inner plexiform layer; INL, inner nuclear layer; OPL, outer plexiform layer; ONL, outer nuclear layer; IS, inner segment; OS, outer segment; RPE, retinal pigment epithelium; BrM, Bruch's membrane; CC, choriocapillaris; $\mathrm{CH}$, choroid. Scale bars in a and $\mathrm{b}=50 \mu \mathrm{m}$, scale bar in $\mathrm{c}=5 \mu \mathrm{m}$.

choroid (Figure 1). Although they perform individual tasks to support normal vision, none of these layers can function properly without the others. Below, we briefly discuss these key cells and tissues, focusing largely on Bruch's membrane and the choroid in healthy, aging, and diseased eyes.

\section{Photoreceptor cells}

With the ability to rapidly convert photons of light into electrical impulses, and the need for constant regeneration of the outer segment, photoreceptor cells are highly metabolically active cells. This enormous level of activity calls for an abundant supply of oxygen; as a result, photoreceptor cells have the highest level of oxygen consumption per gram of any cell type in the body. ${ }^{4}$ This need is met by the unique structure of the choriocapillaris (discussed in section 1.4), which allows for remarkable perfusion of the outer retina. Because of their oxygen requirement, it is easy to imagine how hypoxic conditions would be detrimental for photoreceptor cell health.

Photoreceptor cell loss has been observed in donors with very advanced age ( $>90$ years old), with slight cone loss occurring in the fovea (central $0.8 \mathrm{~mm}$ of the macula) and about a 30\% loss of rods in the parafovea (the region that circumscribes the fovea with a radius of $1.25 \mathrm{~mm}$ on all sides ${ }^{5}$ ). Overall, it has been estimated that two rods per $\mathrm{mm}^{2}$ are lost per year in a healthy retina. ${ }^{6}$ In eyes with advanced dry AMD, this loss is not significantly different, but it appears to be more localized to the area within $1 \mathrm{~mm}$ of the center of the fovea. ${ }^{6}$ In regions of GA or choroidal neovascularization (CNV), severe loss of rods can be observed, whereas cones are largely unaffected. Therefore, although cones are more prevalent in the macula compared with the peripheral retina, rods are the photoreceptors most affected during AMD progression. ${ }^{6,7}$

\section{Retinal pigment epithelium}

The retinal pigment epithelium (RPE) is a single layer of hexagonal epithelial cells. These columnar epithelial cells are especially tall and narrow in the macula, with densely packed pigment granules. Outside the macula, the epithelium gradually transitions to a wider, more cuboidal morphology. The apical surface of the RPE faces the photoreceptor cells and is covered with microvilli that surround the outer segments to aid in their turnover. On their basal side, RPE cells are anchored by hemidesmosomes to their basal laminae, which makes up the innermost layer of Bruch's membrane and overlies the 
choriocapillaris. Beyond its role in phagocytosing and recycling shed photoreceptor outer segments, the RPE is also involved in absorbing excess light, converting alltrans retinol to 11-cis retinal as part of the visual cycle, secreting growth factors to maintain photoreceptor cells and choroidal vasculature, transporting nutrients and waste materials between photoreceptor cells and choriocapillaris, and forming the outer blood-retinal barrier. $^{8}$

Changes in pigmentation are among the most significant and noticeable changes to occur in RPE cells with age. During normal aging, the appearance of the RPE layer becomes altered because of a decrease in the number of melanosomes, an increase in the number of lipofuscin granules, and an increase in toxic visual cycle byproducts. ${ }^{9}$ Furthermore, RPE cells are lost with normal aging, although this loss is relatively minor. ${ }^{10}$ In both aging and AMD eyes, the RPE is thought to be the primary contributor to the lipid component of drusen. ${ }^{11}$

\section{Bruch's membrane (BrM)}

The RPE and choroid are separated by Bruch's membrane (BrM), a 2-4- $\mu$ m-thick extracellular matrix complex that is composed primarily of elastin and collagen. BrM consists of the following five distinct layers: (1) the RPE basement membrane (innermost layer), (2) the inner collagenous layer, (3) the elastic layer, (4) the outer collagenous layer, and (5) the choriocapillary endothelial cell basement membrane (outermost layer; ${ }^{12}$ Figure 2). In addition to elastin, BrM contains collagen type I, III, IV, V, and VI, laminin, fibronectin, heparin sulfate proteoglycans (HSPGs), and chondroitin sulfate (reviewed by Bhutto

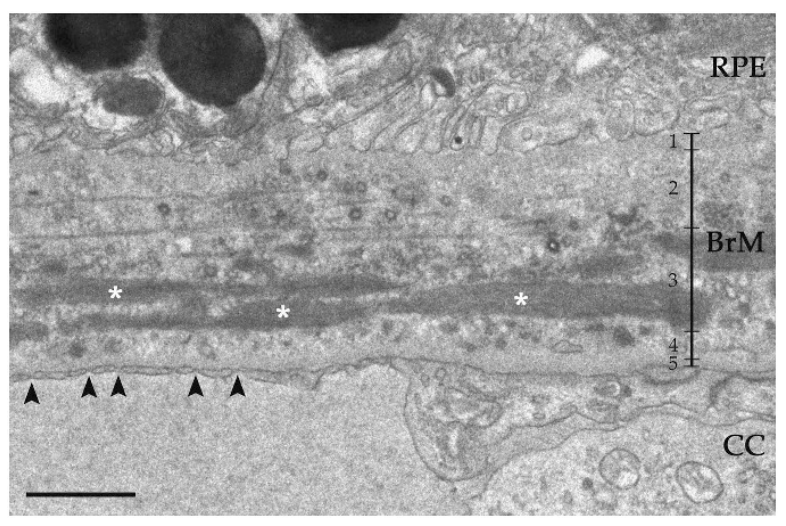

Figure 2 Ultrastructure of BrM. TEM image shows the basal side of the retinal pigment epithelium, all layers of $\mathrm{BrM}$ ( 1 = retinal pigment epithelium basement membrane; $2=$ inner collagenous layer; $3=$ elastic layer, asterisks; $4=$ outer collagenous layer; $5=$ choriocapillary endothelial cell basement membrane), and the apical side of the choriocapillaris with fenestrations (arrowheads). RPE $=$ retinal pigment epithelium; $\mathrm{BrM}=$ Bruch's membrane; $\mathrm{CC}=$ choriocapillaris. Scale bar $=1 \mu \mathrm{m}$. and Lutty ${ }^{13}$ ). The primary functions of BrM include acting as a filter to various molecules that pass between RPE and choroid, and serving as a barrier to prevent aberrant cell migration from the retina or choroid, as BrM contains a reservoir of anti-angiogenic molecules. ${ }^{14}$ In addition, BrM provides a surface for RPE cell adhesion, growth, and physical support. ${ }^{15}$ Various changes occur within BrM during aging and AMD progression, as discussed in sections 4.2 and 4.4 .

\section{Choroid}

The choroid is the vascular bed that lies just beneath the RPE, between BrM and the sclera. The capillary bed (the choriocapillaris), which makes up the innermost layer of the choroid, is the principal blood supply to the outer retina (that is, RPE and photoreceptor cells), and loss of choriocapillary endothelial cells is a key contributor to the development of AMD. As the choroid is a main focus of this review, more detailed descriptions of the choroid are presented below.

\section{Risk factors for AMD}

Owing to the multifactorial nature of AMD, an incomplete picture of disease pathogenesis still remains. Nevertheless, several factors associated with disease risk have been established, with age being the most important. Disease is most likely to occur in individuals over the age of 60; however, the risk for AMD development continues to increase dramatically with age. Ethnicity is also associated with disease risk, with Caucasians at a significantly higher risk for AMD than African Americans in the United States, especially with regard to wet $\mathrm{AMD}^{16}$ (reviewed by Lambert et al ${ }^{17}$ ). Global AMD prevalence by the ethnic group is estimated at: $12.3 \%$ for European ancestry, $10.4 \%$ for Hispanics, $7.5 \%$ for African ancestry, and $7.4 \%$ for Asians. ${ }^{2}$ An important environmental risk factor for AMD is cigarette smoking, which increases the chance of disease by two to three times compared with individuals who have never smoked. This risk increases to at least fourfold when considering wet AMD alone. ${ }^{18}$

\section{Genetics}

Genetics also have an important role in AMD risk. Shahid et al $^{19}$ reported a positive parental and sibling history for AMD, with odds ratios of 36.4 (CI 4.9 to 270.0) and 15.1 (CI 4.6 to 50.0), respectively, after adjusting for age and smoking history. Over the last decade, $\sim 40$ genes have been associated with AMD, including those that make up the complement cascade and its regulators. Some of the polymorphisms in complement genes that have a strong association with AMD are those in the C3 (rs2230199), CFI 
(rs10033900), and CFH (rs1061170) genes, as well as the C2/CFB locus (rs9332739, rs547154, rs4151667, and rs641153), with the CFH Y402H polymorphism increasing AMD risk by up to sevenfold. ${ }^{20-26}$ The complement component 2 (C2) and complement factor B (CFB) genes are separated by $\sim 500$ bp and are located within the major histocompatibility complex class III region of chromosome 6p21. Two major variants in C2 (rs9332739 and rs547154) are in near-complete linkage disequilibrium with two major variants in CFB (rs4151667 and rs641153), respectively, and both confer a decreased risk for AMD. ${ }^{24}$ The disease-associated CFI polymorphism (rs10033900) also reduces AMD risk. ${ }^{27}$ A more complete review of complement-associated genetic risk factors can be found in Khandhadia et $\mathrm{al}^{28}$ and an overview of the complement system components and their functions is provided below in sections 4.5 and 4.6 .

Whereas complement genes make up some of the most significant and well-studied genes associated with AMD risk, other factors have been linked strongly to AMD. Polymorphisms in the ARMS2/HTRA1 locus, such as the A69S SNP (rs10490924) in ARMS2, as well as other variants in the ARMS2 and HTRA1 genes, are associated with increased risk for AMD. ${ }^{29}$ Owing to almost complete linkage disequilibrium between the ARMS2 and HTRA1 variants, identifying the causal role of variant(s) within this locus remains difficult.

In addition to their association with AMD risk, genetic changes are associated with an altered molecular composition of the choroid. These inherited differences in choroidal biochemistry may also contribute to disease pathogenesis (discussed in section 3.3).

\section{Drusen, basal deposits, and reticular pseudodrusen}

Drusen are defined as extracellular deposits that accumulate beneath the RPE within BrM. They can be visualized upon fundoscopic examination and appear as yellowish-white lesions within the macula (in the case of AMD). The traditional system used for classifying drusen provides the following two major druse types: (1) hard drusen, which are well-delineated and typically small ( $<63 \mu \mathrm{m}$ in diameter) and (2) soft drusen, which can range from small to large (between 63 and $125 \mu \mathrm{m}$ ) and have distinct or indistinct borders. ${ }^{30}$ Druse size, density, and number are the key factors in determining risk for AMD progression. ${ }^{30}$ Observations from various groups indicate that larger drusen form by the fusion of smaller drusen. ${ }^{31,32}$ Studies using donor eye whole mounts indicate that drusen deposition tends to occur over intercapillary pillars in the peripheral choroid, which supports the hypothesis that inefficient clearance of waste/debris by the choriocapillaris (whether that is due to degeneration of the choriocapillaris or a thickening of
BrM) is an important event in AMD. ${ }^{32}$ In addition, an inverse relationship has been observed between the extent of drusen within the macula and choroidal blood flow beneath the fovea, ${ }^{33}$ as well as drusen density and CEC loss. ${ }^{34}$

Whereas drusen are histologically apparent as isolated and elevated mounds of sub-RPE material, basal deposits tend to be flat and contiguous. Basal deposits come in two distinct ultrastructural forms: basal laminar deposits and basal linear deposits. Basal laminar deposits are made up of extracellular matrix components that accumulate between the RPE and its basement membrane (innermost layer of BrM). In contrast, basal linear deposits consist of lipidic membranous debris and form between the RPE basement membrane and the inner collagenous layer of $\mathrm{BrM}$, in the same site as drusen. Basal linear deposits or large drusen are associated with early AMD with an OR $=24.0$ (3.52-163.75). ${ }^{35}$

Similar to basal linear deposits and soft drusen, reticular pseudodrusen (RPD) primarily consist of membranous debris; however, they form above the RPE. Interestingly, RPD can be somewhat transient formations that largely spare the fovea. ${ }^{36}$ Curcio et al went on to find that RPD preferentially localize to the perifovea, where rod density is highest. ${ }^{37}$ Others have found that RPD tend to occur within or very near to choroidal watershed zones, which are at the border between two or more separate regions of perfusion, which have comparatively poor vascularity and are vulnerable to ischemia.

Before any observable retinal alterations, early RPD development coincides with choroidal thinning, ${ }^{38,39}$ as well as an increase in the ratio of stromal to total choroidal area. ${ }^{39}$ Thorell et al ${ }^{40}$ showed that intermediate or advanced dry AMD patients with RPD had thinner choroids below the fovea compared with age-matched controls. These data support the idea that reduced blood flow within the macular choriocapillaris is involved in early AMD pathophysiology.

Drusen and other extracellular deposits may stress the overlying RPE and retina by accumulating toxic substances, obstructing the passage of nutrients and oxygen from the choriocapillaris (if it has not already degenerated), or eliciting an immune response. These deposits may also serve as a site for the invasion of $\mathrm{CNV}$ (Figure 3).

\section{Overview of the healthy choroid}

Understanding the development, function, structure, and molecular composition of the normal choroid helps us to better evaluate the tissue in disease states, and also provides insight into what types of treatments may be the most useful to stop or reverse AMD or other diseases affecting this tissue. 


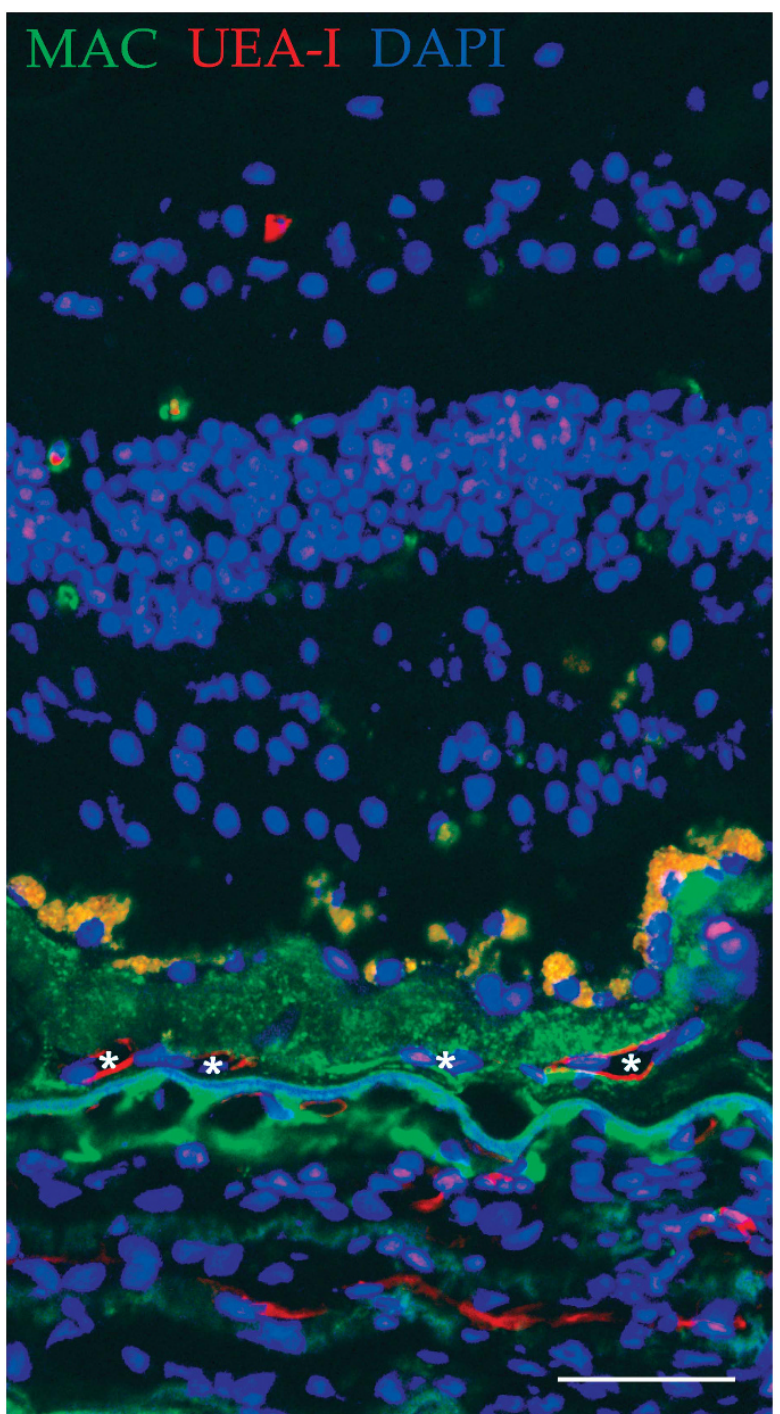

Figure 3 Drusen as a site for CNV invasion. Immunofluorescence image from a human donor with wet AMD exhibits vessels (Ulex europaeus agglutinin I, UEA-I; red; asterisks) present within the druse deposit, who also contains high levels of the MAC (green). Section was counterstained with DAPI (blue). Scale $\mathrm{bar}=50 \mu \mathrm{m}$.

\section{Choroid function and structure}

The innermost layer of the choroid, lying just behind BrM, is the choriocapillaris. This dense, single layer of broad capillaries is fenestrated, especially on the retinal surface, to allow the passage of oxygen and nutrients to the RPE and photoreceptor cells, while also removing waste products via the systemic circulation. The choriocapillaris is organized in a lobular pattern, creating various watershed zones, which are especially susceptible to hypoxia and RPD development ${ }^{38}$ (see section 2.2). In the posterior pole, a layer of intermediate arterioles and venules (Sattler's Layer) exists and connects the choriocapillaris to the arteries and veins located in the outer choroid (Haller's Layer). In the peripheral choroid, the choriocapillaris connects directly to larger caliber vessels, with fewer intermediate channels. The long and short ciliary arteries, which branch from the ophthalmic artery, are the primary sources of blood that feed the choroidal vasculature, which subsequently drains through four or five vortex veins at the equator (typically one vein per quadrant of the posterior pole ${ }^{41}$ ). Blood flow in the choroid is regulated by the autonomic nervous system, and is controlled at the arteriolar level. Arterioles of the choroid are innervated by both adrenergic nerves (superior cervical ganglion) and parasympathetic nerves (pterygopalatine ganglion of the facial nerve), which, respectively, induce vasoconstriction and vasodilation upon stimulation. ${ }^{42}$ Regulation of choroidal blood flow differs from that of retina, as retinal blood flow is controlled via autoregulation and therefore lacks autonomic innervation. ${ }^{42}$ Perivascular smooth muscle cells (or pericytes in the choriocapillaris) wrap around the arteries/arterioles to regulate vascular tone.

The connective tissue surrounding the vessels (the choroidal stroma) comprises additional neurons and nerve processes, melanocytes, fibroblasts, non-vascular smooth muscle cells, and leukocytes (see section 3.3.3), as well as collagen, elastin, and other extracellular matrix components. Non-vascular smooth muscle cells primarily exist in a single layer beneath $\mathrm{BrM}$ and in the suprachoroid (the transition zone between the choroid and the sclera), with the highest concentration of cells residing beneath the fovea. These cells may be involved in regulating choroidal thickness, at least in cases of retinal defocus. ${ }^{43}$

\section{Development of the choroid}

The choriocapillaris is unusual in its development compared with most other capillary beds in the body. The choriocapillaris develops via hemovasculogenesis between 6- and 8-week gestation, before the formation of intermediate or large vessels. At 11- to 12-week gestation, the development of intermediate choroidal vessels within the Sattler's layer is observed and occurs by angiogenesis; this process allows for the choriocapillaris to connect with the larger, outer choroidal vessels of Haller's layer. Three distinct layers of choroidal vessels can be seen at 21-week gestation, which coincides with the beginning of photoreceptor cell differentiation. Interestingly, the three layers of the choroid (the choriocapillaris, Sattler's layer, and Haller's layer) are notable only in the posterior pole, whereas the choroid outside the posterior pole consists of choriocapillaris and a layer of larger vessels only. ${ }^{44}$ The choriocapillaris appears fully mature at 22-week 
gestation, with flat, thin-walled vessels that already exhibit fenestrations ${ }^{44,45}$ (reviewed by Lutty et al ${ }^{46}$ ).

\section{Molecular composition of the choroid}

However, similar in many respects to other vascular beds, the choroid has several distinctive features that are important for its normal function and disease pathology.

Human leukocyte antigen class I expression Human leukocyte antigen (HLA) class I proteins are expressed on the surface of most cells in the human body. Members of the HLA family mediate immune responses through their ability to differentiate between self and non-self cells. Immunohistochemical labeling for HLA class I antigens in the retina and choroid shows localization of these antigens primarily to the endothelial cells of the choriocapillaris, with weaker labeling of larger choroidal vessels. Occasional labeling along the basal aspect of RPE cells has also been described. ${ }^{47-49}$ This observation becomes especially relevant when cell replacement therapy is the only option for restoring vision in patients with advanced degeneration (see section 5). The presence of HLA class I antigens on endothelial cells of the choroid suggests the strong possibility for an immune response and rejection if non-HLA-matched cells are used for transplantation. Apart from T-cell-mediated rejection (graft $v$ s host disease), anti-HLA antibodies against donor endothelial cell HLAs could induce complement activation, cytokine production, unwanted endothelial cell proliferation, and ultimately result in donor cell cytotoxicity. ${ }^{50}$ The best way to circumvent this potential for rejection is to use autologous cells, such as patientspecific induced pluripotent stem cell (iPSC)-derived CECs to replace lost endothelial cells of the choriocapillaris (discussed in section 5.3).

ICAM-1 and CA4 Intracellular adhesion molecule 1 (ICAM-1) is a glycoprotein typically expressed on the surface of immune and endothelial cells. As part of the immunoglobulin superfamily, ICAM-1 binds circulating leukocytes via CD11a/CD18 or CD11b/CD18 integrins to aid in their transmigration across the endothelium. In most vascular beds, ICAM-1 is only expressed in response to the presence of pro-inflammatory cytokines during an immune response. In contrast, ICAM-1 is constitutively expressed on endothelial cells of the healthy choriocapillaris, especially within the macula. ${ }^{51,52}$ Of note, elevated ICAM-1 has been described in association with $\mathrm{AMD}, 53,54$ and could promote the recruitment of leukocytes into the choroid to evoke or propagate an immune response. Its expression is increased in organcultured choriocapillaris by $\mathrm{C} 5 \mathrm{a}^{55}$ and LPS, with attenuation of new expression by AREDS vitamins. ${ }^{56}$
CA4 immunolabeling is visible in the developing choriocapillaris as early at 8-week gestation, with CA4 observed in all three layers of choroidal vasculature by 21-week gestation. ${ }^{45}$ By adulthood, CA4 is abundant in the endothelial cells of healthy human choriocapillaris, but is absent in the larger vessels of Sattler's and Haller's layers. ${ }^{57}$ Therefore, in healthy eyes CA4 can be used as a specific marker for choriocapillary endothelial cells, where it is likely involved in the interconversion of $\mathrm{CO}_{2}$ and bicarbonate ions across the choriocapillary vessel wall, as well as local pH regulation. Interestingly, partial loss-of-function mutations in CA4 that affect its ability to regulate $\mathrm{pH}$ result in severe photoreceptor degeneration, ${ }^{58}$ highlighting the importance of CA4, and proper $\mathrm{pH}$ regulation, for healthy retinal function. Whereas diabetic eyes with intra-CNV ${ }^{59}$ show CA4 expression on the aberrant capillaries (unpublished observations), CA4 protein abundance is actually decreased in eyes with AMD. ${ }^{60}$

Leukocytes in the choroid Two main types of leukocytes have been studied in the choroid, the mast cell and the macrophage, both of which may have a significant role in AMD pathogenesis.

Mast cells are abundant in the healthy human choroid, ${ }^{61}$ and they are primarily observed in the stroma around the blood vessels of Haller's and Sattler's layers in aged control eyes. ${ }^{62,63}$ Bhutto et al found that in eyes with early or late stage $\mathrm{CNV}$, mast cells reside around or within BrM, sometimes crossing through breaks in BrM. ${ }^{63}$ In early AMD eyes, mast cells are significantly more abundant in the choroid compared with control eyes, and many of those cells appear to be degranulated. Eyes with GA exhibit degranulated mast cell localization within Sattler's layer and the choriocapillaris in regions bordering RPE atrophy, as well as regions with complete RPE or choriocapillaris atrophy. The areas with the greatest abundance of degranulated mast cells correspond to the areas with significant choriocapillaris degeneration. ${ }^{63}$ Mast cells have also been shown to interact with endothelial cells to induce angiogenesis. ${ }^{63}$ Furthermore, C-reactive protein (CRP) binds mast cells via the FcyRIIa receptor ${ }^{64}$ and stimulates the release of histamine. ${ }^{65}$ This interaction is likely between FcyRIIa and CRP monomers (mCRP) specifically, as this form can easily and spontaneously dissociate in in vitro conditions similar to those used by these authors.

Healthy human eyes contain CD68+ macrophages throughout the choroidal stroma; however, these macrophages remain many microns away from BrM. ${ }^{66}$ In early AMD, macrophages become visible beneath BrM within intercapillary pillars or in place of capillaries altogether. As disease advances, macrophage abundance increases in the choriocapillaris, with the greatest 
numbers observed in eyes with subclinical CNV. BrM/ choriocapillary macrophages are also present at the border of atrophy in eyes with GA, but not within GA lesions. ${ }^{66}$ Interestingly, Wang et al ${ }^{67}$ found more CD68+ cells in the choroids of high-risk (CFH CC) eyes compared with controls. Together, these studies suggest a role for macrophages in early-disease pathogenesis, and in the development of CNV. A more detailed description of macrophages in the aging and AMD choroid is beyond the scope of this review; an in-depth review can be found in Skeie and Mullins. ${ }^{68}$

\section{Vascular changes with aging and disease}

The choroid and its vasculature undergo various changes during normal aging, and these changes often become more severe in eyes with AMD. Whereas some of these changes are likely a cause or contributing factor for disease onset, others may instead be a result of AMD pathology.

\section{Choriocapillary vascular dropout and changes to choroidal thickness with age}

Choroidal thickness has been shown to be somewhat plastic, with rapid changes of up to $100 \mu \mathrm{m}$ occurring within hours of a myopic defocus stimulus in chickens (reviewed by Nickla and Wallman ${ }^{69}$ ). Furthermore, choroidal thickness fluctuates daily in chicks by up to $40 \mu \mathrm{m}$ between midnight (thickest) and noon (thinnest), exhibiting a diurnal pattern. ${ }^{69}$ In these instances, nonvascular smooth muscle cells, altered proteoglycan synthesis and degradation, or a change in the fluid flux into the choroid are the likely mediators of rapid and reversible modulation of choroidal thickness. Reversible changes in choroidal thickness in humans are much smaller in magnitude. ${ }^{70,71}$ However, the aging choroid seems to undergo a more drastic, permanent change to choroidal thickness. Using swept-source OCT, Wakatsuki et $a l^{72}$ assessed choroidal thickness in healthy control patients with patient age ranging from 21 up to 85 years. They found that total choroidal thickness decreases with age, with the thickness of the choroid beneath the fovea decreasing by $\sim 3 \mu \mathrm{m}$ per year.

\section{Age-related changes to BrM}

With age, the layers of BrM become less distinct and the entire structure becomes thicker. Moreover, in addition to the significant accumulation of lipids ${ }^{11}$ (described elsewhere in this volume) and the formation of drusen, $\mathrm{BrM}$ undergoes various age-related changes that may contribute to AMD pathogenesis. One of these changes includes a loss of $\sim 50 \%$ of the HSPG levels in macular
BrM between the ages of $\sim 30$ and 80 years. ${ }^{73}$ As the overall abundance of HSPG changes with age, HSPG composition undergoes a slight, but significant change as well. The degree of HSPG sulfation, which is important for $\mathrm{CFH}$ binding, decreases with age. Although the $402 \mathrm{H}$ form of $\mathrm{CFH}$ has about a 30\% reduction in binding to $\mathrm{BrM}$ compared to the $402 \mathrm{Y}$ form, this impaired binding becomes significantly more pronounced with age. ${ }^{73}$

Another age-related change that occurs within BrM that may contribute to AMD is the accumulation of advanced glycation end products (AGEs). AGEs are proteins or lipids that are covalently bound with sugar molecules. In contrast to physiological glycosylation that takes place intracellularly in the endoplasmic reticulum and Golgi, the formation of AGEs takes place non-enzymatically and extracellularly. AGEs preferentially accumulate in extracellular matrices, such as BrM, and disrupt normal protein function. Once AGE accumulation reaches a certain level, the AGE receptor (RAGE) can be engaged and activated. RAGE is present on many cell types, including endothelial cells and leukocytes, and its activation induces an inflammatory response that could help trigger the conversion from acute inflammation to chronic inflammation and tissue damage, and may have a role in angiogenesis. RAGE may also contribute to the activation of immune cells in laser-induced CNV lesion in a mouse model of AMD. ${ }^{74}$

\section{Choriocapillary vascular dropout and changes to choroidal thickness in AMD}

Upon assessment of the mean choroidal blood flow in patients at risk for CNV development, Grunwald et al ${ }^{75}$ discovered an association between decreased circulation within the choroid and increased risk for wet AMD. These data implicate ischemia in CNV formation, and provide evidence for the importance of decreased choroidal blood flow in disease progression. ${ }^{75}$ Furthermore, in histological studies, a decrease in choriocapillaris density was strongly associated with an increase in the number of ghost vessels (Figure 4), suggesting that differences in vascular density are due to loss of endothelial cells, not innate variability in vessel density. ${ }^{34}$

Eyes with GA have a thinner choroid than age-matched controls or those with early AMD. In biochemical studies of donor choroids, thin choroids were found to have higher levels of tissue inhibitor of metalloproteinase-3 (TIMP3), whereas thicker choroids exhibit higher levels of serine proteases, with corresponding shifts in the balance between fibrillar collagen and ground substance in the choroidal stroma. ${ }^{76}$ Altered abundance and/or function of proteases or their inhibitors may be an important factor in choroidal thinning and AMD pathogenesis. 


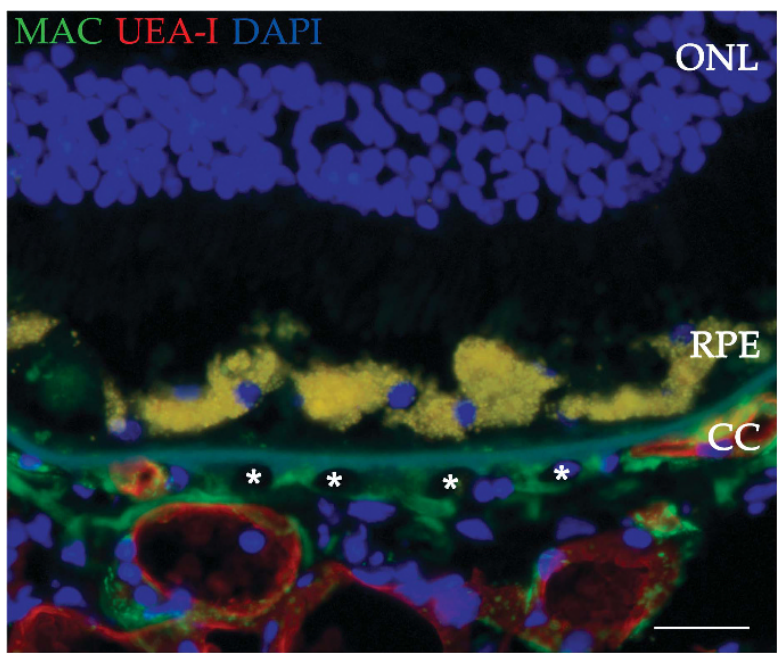

Figure 4 Ghost vessels in the choriocapillaris. Choroidal endothelial cell loss (ghost vessels; asterisks) in a 96-year-old donor with atrophic AMD is indicated by loss of UEA-I lectin labeling (red). The MAC (green) is present throughout the choriocapillaris. The section was counterstained with DAPI (blue). ONL, outer nuclear layer; RPE, retinal pigment epithelium; CC, choriocapillaris. Scale bar $=50 \mu \mathrm{m}$.

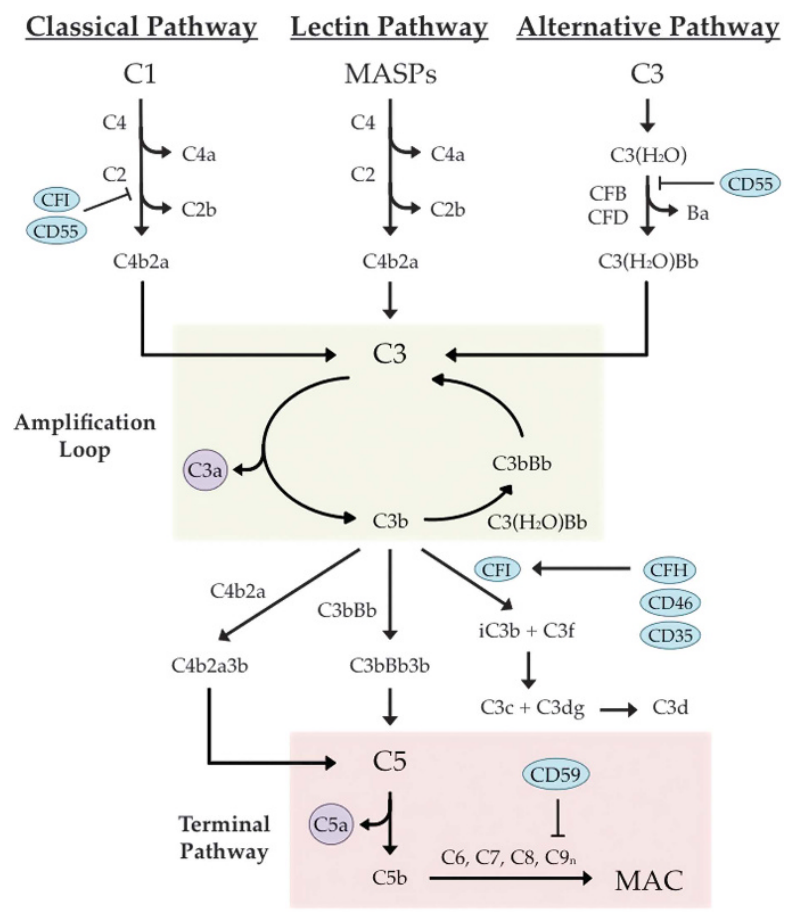

Figure 5 Overview of the complement system. Complement regulators are depicted as blue ovals and anaphylatoxins are presented as purple circles. The alternative pathway amplification loop is highlighted in green and the common terminal pathway is highlighted in red.

\section{AMD-associated changes to CECs and BrM}

Using quantitative proteomics analysis of the macula of human eyes, Yuan et $a l^{60}$ found a decrease in the abundance of the vascular protein von Willebrand factor in the $\mathrm{BrM} /$ choroid tissue from donor eyes with early- or mid-stage AMD compared with controls, whereas CA4 levels were reduced in advanced dry AMD eyes. Furthermore, HLA class I proteins are less abundant in $\mathrm{BrM} /$ choroid tissue of AMD eyes compared with control. ${ }^{60}$ These proteomic studies indicate loss of vascular markers during AMD progression. Similarly, in exon array mRNA experiments, eyes with early AMD exhibit a trend toward increased expression of RPEspecific genes, and decreased expression of endothelial cell-specific genes, when compared with healthy controls. ${ }^{77}$ These findings suggest that CECs dedifferentiate or become lost before apparent loss of RPE cells in eyes with early AMD.

Because of its vital role as a physical and biochemical barrier, the integrity of BrM is essential to the health of the outer retina and choroid. A physical breakdown in this barrier is present in both aging and in AMD (reviewed by Bhutto and Lutty ${ }^{13}$ ). In AMD eyes, BrM also experiences a shift in its biochemical properties, with a reduction in the levels of potent anti-angiogenic factors ${ }^{14}$ and increased levels of cholesterol and cholesteryl esters. ${ }^{78}$ Such alterations to BrM (in addition to the age-associated changes discussed in section 4.2) could significantly affect diffusion of nutrients and/or waste between outer retina and choriocapillaris, and it may render the tissue susceptible to $\mathrm{CNV}$ invasion.

\section{Membrane attack complex overview}

The complement system is a proteolytic cascade comprising $\sim 40$ plasma and cell surface-associated proteins involved in the elimination of pathogenic cells, dead or dying host cells, and other dangerous cellular debris or particles from the body. The complement system is made up of the following three pathways: the classical pathway, the lectin pathway, and the alternative pathway (Figure 5).

The classical pathway is initiated when the $\mathrm{C} 1$ complex (one C1q, two C1r, and two C1s moieties) interacts with antibody complexes. The activated $\mathrm{C} 1$ complex then cleaves $\mathrm{C} 4$ to produce $\mathrm{C} 4 \mathrm{a}$ and $\mathrm{C} 4 \mathrm{~b}$, and $\mathrm{C} 2$ to produce $\mathrm{C} 2 \mathrm{a}$ and $\mathrm{C} 2 \mathrm{~b}$. The $\mathrm{C} 4 \mathrm{~b}$ and $\mathrm{C} 2 \mathrm{a}$ components can then assemble to form the classical (and lectin) pathway C3 convertase, $\mathrm{C} 4 \mathrm{~b} 2 \mathrm{a}$, which accelerates the cleavage of $\mathrm{C} 3$ into $\mathrm{C} 3 \mathrm{a}$ and $\mathrm{C} 3 \mathrm{~b}$. The lectin pathway is initiated via recognition of pathogen-associated molecular patterns by mannose-binding lectin (MBL), ficolins, or collectin- 11 . MBL, ficolin, or collectin-11 then interacts with MBL serine peptidases to subsequently cleave $C 4$ and $C 2$. At this point, the lectin pathway and the classical pathway share the same downstream constituents. In contrast to the classical and lectin pathways, the alternative pathway is constitutively active. A process called 'tick-over' leads to $\mathrm{C} 3$ hydrolysis to form $\mathrm{C} 3\left(\mathrm{H}_{2} \mathrm{O}\right)$ in the fluid phase 
(reviewed by Nilsson and Nilsson Ekdahl ${ }^{79}$ ). Once CFB binds $\mathrm{C} 3\left(\mathrm{H}_{2} \mathrm{O}\right), \mathrm{CFB}$ can be cleaved by complement factor $\mathrm{D}$ into $\mathrm{Ba}$ and $\mathrm{Bb}$, and $\mathrm{Bb}$ stays bound to $\mathrm{C} 3\left(\mathrm{H}_{2} \mathrm{O}\right)$. The alternative pathway $\mathrm{C} 3$ convertase $(\mathrm{C} 3 \mathrm{bBb})$ is then formed when the $\mathrm{C} 3\left(\mathrm{H}_{2} \mathrm{O}\right) \mathrm{Bb}$ serine protease cleaves $\mathrm{C} 3$ into $\mathrm{C} 3 \mathrm{a}$ and $\mathrm{C} 3 \mathrm{~b}$, allowing $\mathrm{C} 3 \mathrm{~b}$ to bind the $\mathrm{Bb}$ molecule. The formation of $\mathrm{C} 3 \mathrm{bBb}$ generates an amplification loop in which $\mathrm{C} 3$ is cleaved to form more C3b.

Whereas these three pathways have distinct mechanisms of initiation, they all utilize the same terminal pathway involving $\mathrm{C} 5$ cleavage. Once $\mathrm{C} 3$ is cleaved and the levels of $\mathrm{C} 3 \mathrm{~b}$ begin to increase, $\mathrm{C} 5$ convertases are formed (C4b2a3b and $\mathrm{C} 3 \mathrm{bBb} 3 \mathrm{~b})$. These enzymes cleave $\mathrm{C} 5$ to generate $\mathrm{C} 5 \mathrm{a}$ and $\mathrm{C} 5 \mathrm{~b}$, the latter of which interacts with $\mathrm{C} 6, \mathrm{C} 7, \mathrm{C} 8$, and many copies of $\mathrm{C} 9$ to form the membrane attack complex (MAC). MAC formation is the final step in complement activation and it results in target cell lysis. In addition to formation of the $\mathrm{MAC}$, the complement cascade produces potent anaphylatoxins (C3a and $\mathrm{C} 5 \mathrm{a}$ ), which aid in efficient clearance of lysed cells through phagocyte recruitment and leukocyte and endothelial cell activation.

In order to prevent the activation of complement beyond what is necessary to effectively clear a pathogen or damaged cell, an array of regulatory proteins exists. Membrane inhibitory proteins, such as protectin (CD59), MCP (CD46), DAF (CD55), and CR1 (CD35), as well as fluid-phase proteins, such as complement factor $\mathrm{H}$ (CFH) and complement factor I (CFI), act as inhibitors of complement to help keep its activation under tight control.

One of the key complement proteins in AMD pathogenesis is $\mathrm{CFH}$, which aids in the regulation of the alternative pathway through the inactivation of C3b. Upon binding to $\mathrm{C} 3 \mathrm{~b}$ on target membranes, $\mathrm{CFH}$ recruits CFI that acts to cleave $\mathrm{C} 3 \mathrm{~b}$ into inactive fragments $(\mathrm{iC} 3 \mathrm{~b}$ and C3f). In addition, CFH is abundant in human plasma, at a concentration of $\sim 2 \mu \mathrm{M}$, where it can suppress the amplification of the fluid-phase C3b-like molecule, C3 $\left(\mathrm{H}_{2} \mathrm{O}\right)$. Although it is primarily produced in the liver, CFH is also expressed in RPE and endothelial cells. ${ }^{80}$ Various studies have shown that $\mathrm{CFH}$ recognizes and binds to sialic acids and glycosaminoglycan chains, such as HSPG. CFH is traditionally thought of as a regulator specific to the alternative pathway; however, there is evidence to suggest its role in classical pathway regulation as well. For example, mCRP, which activates the classical complement pathway, ${ }^{81}$ is bound by CFH presumably to aid in the regulation of mCRP-mediated complement activation. Furthermore, recruitment of $\mathrm{CFH}$ to damaged cells via classical pathway-activating damage-associated molecular patterns has been suggested $^{82}$ (reviewed by Makou et al ${ }^{83}$ ).

\section{The relationship between the MAC and AMD}

In the previously mentioned proteomic studies of donor maculas, ${ }^{60}$ TIMP3 as well as the complement proteins, C7, $\mathrm{C} 5$, and $\mathrm{C} 9$, were found to be more abundant in $\mathrm{BrM}$ / choroid tissue from early- or mid-stage AMD eyes compared with controls. Interestingly, complement C3 protein levels were elevated in advanced wet AMD eyes compared with control. These data provide evidence for inflammatory processes, including complement activation, as early factors in disease progression with the potential to be triggers for AMD development. ${ }^{60}$

When C9 is assembled into the MAC, novel epitopes are revealed that can be detected with monoclonal antibodies, and this property has been valuable in identifying and quantifying the MAC in human eyes (Figure 6). Donors homozygous for the high-risk CFH
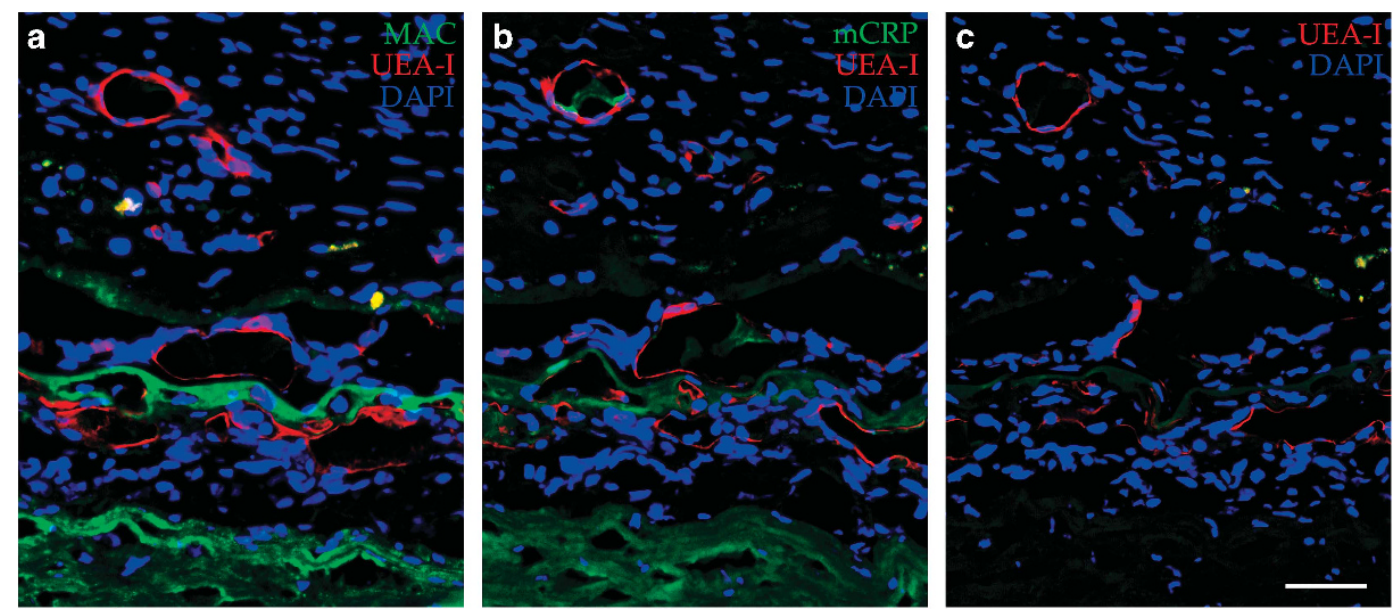

Figure 6 Membrane attack complex and monomeric C-reactive protein accumulation in wet AMD. An anti-C5b-9 antibody directed against the MAC ( $a$, green), and an anti-mCRP antibody ( $b$, green) were utilized in sections from a wet AMD donor. A secondary control shows UEA-I lectin only (c, red). All sections were counterstained with DAPI. Scale bar $=50 \mu \mathrm{m}$. 
$\mathrm{Y} 402 \mathrm{H}$ polymorphism were found to have choroidal MAC levels $69 \%$ higher than that of the low-risk donors. ${ }^{84}$ In a number of studies, the MAC has been localized to the aging choriocapillaris, as opposed to retina or RPE. ${ }^{85,23}$ In a study of 100 genotyped eyes, we found that MAC immunolabeling within the healthy choriocapillaris increases with age, beginning as early as 2 years of age. ${ }^{86}$ In donor eyes with advanced AMD, the MAC can be seen outside regions of GA but is abundant in the choriocapillaris in regions of $\mathrm{CNV}$, even after loss of endothelium had occurred. ${ }^{86}$ Moreover, the choroids of eyes homozygous for the high-risk CFH Y402H allele have elevated MAC deposition in the choriocapillaris and are almost $24 \%$ thinner compared with low-risk eyes. In addition to an association between age and deposition of the MAC, these data suggest an association between the high-risk CFH genotype and increased choroidal atrophy, which may be due to the observed increase in MAC accumulation around the vessels in high-risk donor eyes. ${ }^{86}$ The MAC preferentially accumulates in the healthy, aging choriocapillaris when compared with other capillary beds, which may provide the basis for the absence of systemic phenotypes in patients with AMD. ${ }^{87}$ The anatomic and molecular properties of the choriocapillaris responsible for this specificity are not yet known.

The consequences of direct exposure to the MAC in vitro include CEC death and upregulation of proangiogenic factors in surviving cells, leading to $\mathrm{CNV}$ formation. ${ }^{88}$ Therefore, the previously observed deposition of the MAC around the endothelium of the choriocapillaris may lead to cell lysis and death early in disease, and could be a major trigger for AMD progression.

\section{CRP overview}

As a member of the pentraxin family of fluid-phase pattern recognition molecules, native or pentameric CRP $(\mathrm{pCRP})$ is an acute-phase protein whose expression is increased up to 1000 -fold in the liver within $24 \mathrm{~h}$ after inflammation or tissue damage has begun. The induction of CRP expression is initiated primarily by the presence of IL-6, and to a lesser degree by IL- $1 \beta$ and TNF, in the liver. ${ }^{89}$ Once pCRP has been synthesized, the liver releases the cyclic homopentamer into circulation, leading to an increase in serum pCRP levels from $<1$ up to $>500 \mu \mathrm{g} / \mathrm{ml}$. As a result, the serum-associated pCRP is commonly used as a biomarker for infection or inflammation, regardless of the cause. Importantly, pCRP exhibits net anti-inflammatory activity. However, pCRP can dissociate into monomers (mCRP) and adopt potent pro-inflammatory properties. The triggers that cause dissociation into mCRP include binding to activated platelets or damaged or apoptotic cells (via lysophosphatidylcholine). ${ }^{90}$

mCRP activates the classical complement pathway while aiding in the regulation of the alternative pathway (discussed above). More specifically, mCRP is able to bind $\mathrm{C} 1 \mathrm{q}$ and activate the classical pathway in a dosedependent manner. In addition, $\mathrm{mCRP}$ binds $\mathrm{CFH}$ to regulate alternative pathway activation, and this regulation is also dose-dependent. ${ }^{81}$ Importantly, the binding affinity between mCRP and mutant CFH $(402 \mathrm{H})$ is as much as $45 \%$ lower than that of mCRP and wild-type $\mathrm{CFH}(402 \mathrm{Y}) ;{ }^{91}$ this is because the $\mathrm{Y} 402 \mathrm{H}$ variation occurs in the CCP7 domain, which is one of the two CCP regions that interact with mCRP. ${ }^{91,92}$

Pasceri et $a l^{93}$ showed that exposing HUVECs to CRP (presumably $\mathrm{mCRP}$ ) results in the upregulation of ICAM-1, VCAM-1, and E-selectin by the cells, indicating a pro-inflammatory response. Furthermore, direct treatment of ARPE-19 cells with mCRP results in a dosedependent increase in IL-8 and CCL2 expression. ${ }^{94} \mathrm{We}$ recently found that CECs exposed to $\mathrm{mCRP}$ increase their migration and monolayer permeability in vitro. In addition, stimulating human RPE/choroid organ cultures with $\mathrm{mCRP}$ results in the upregulation of inflammatory response genes, including several cytokines and ICAM-1. These cultures also exhibited a significant decrease in CA4 mRNA levels, suggesting a role for mCRP in AMDrelated vascular dysfunction. ${ }^{95}$

\section{The relationship between CRP and AMD}

Elevated levels of serum CRP are significantly associated with AMD risk ${ }^{96}$ and progression rate. ${ }^{97}$ Serum CRP levels and $\mathrm{CFH}$ polymorphisms are independently associated with AMD risk, ${ }^{98}$ and therefore the high-risk $\mathrm{CFH}$ polymorphism in combination with elevated levels of serum CRP has an additive effect on risk of AMD progression. ${ }^{99}$ In addition, donor eyes from individuals with the high-risk $\mathrm{CFH}$ genotype (CC, $n=6$ ) have $\sim 2.5$ times more total CRP in the choroid compared with lowrisk eyes $(n=9) .{ }^{100}$ When compared with age-matched controls, early AMD and wet AMD eyes exhibited elevated levels of total CRP in the choriocapillaris and $\mathrm{BrM}$, whereas areas of GA in eyes with advanced dry AMD showed less CRP immunolabeling. The converse pattern was observed for $\mathrm{CFH}$ in early and wet AMD eyes, with $\mathrm{CFH}$ levels significantly lower in the choriocapillaris and BrM compared with age-matched controls. ${ }^{101}$ When mCRP and pCRP were analyzed separately in the choroids of high-risk vs age-matched control eyes, mCRP was found to be the only form present in the choriocapillaris. ${ }^{95}$ Furthermore, in a study of eyes from 50 genotyped donors, high-risk eyes had significantly more mCRP compared with control eyes 

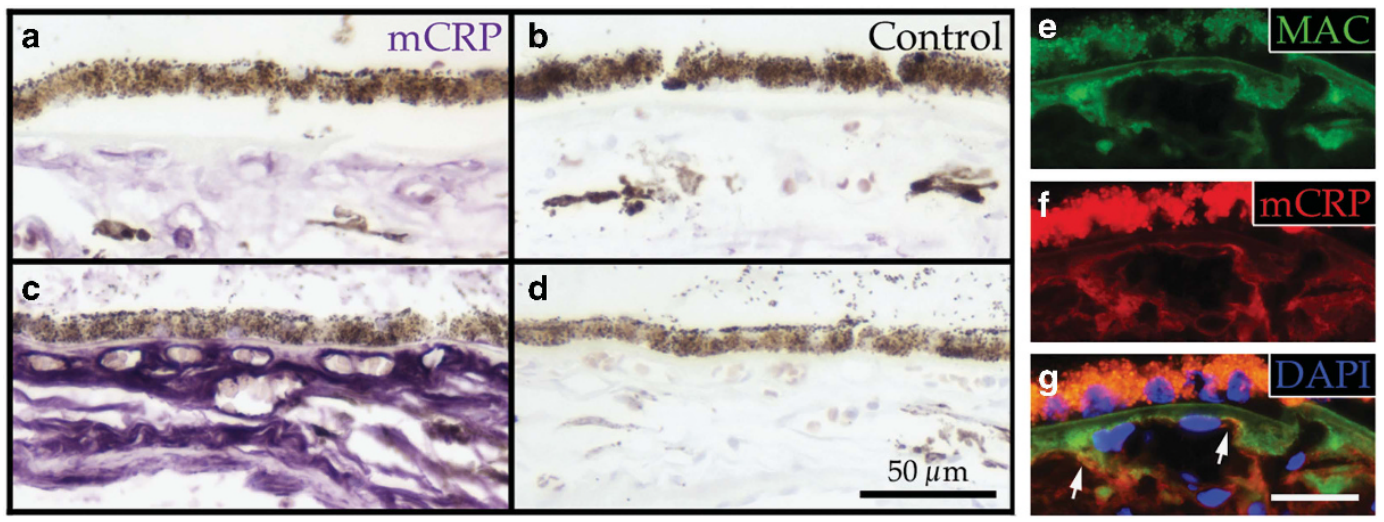

Figure 7 Monomeric C-reactive protein is elevated in the choriocapillaris of high-risk donor eyes and colocalizes with the membrane attack complex. mCRP is more abundant in the choriocapillaris of a donor homozygous for the CFH Y402H polymorphism (c; purple), compared with a control donor (a; purple). Secondary controls for each donor are shown in b and d. An anti-C5b-9 antibody (e and g; green) and an anti-mCRP antibody ( $\mathrm{f}$ and $\mathrm{g}$; red) display regions of co-labeling at the edge of the vessels within the choriocapillaris (g; arrows). DAPI was used as a counterstain in $\mathrm{g}$. Scale bar in $\mathrm{d}=50 \mu \mathrm{m}$, scale bar in $\mathrm{g}=25 \mu \mathrm{m}$.

(Figures 7a-d). Colocalization between the MAC and mCRP was also observed in the choriocapillaris (Figures $7 \mathrm{e}-\mathrm{g}) .^{95}$

On the basis of the known roles for mCRP in complement activation and inflammation, it is feasible that mCRP begins to accumulate in the choriocapillaris before disease onset and acts as a trigger for inflammation within the tissue. These actions, in conjunction with those of the MAC, could overwhelm the choriocapillaris and lead to CEC death. Alternatively, mCRP may dissociate from pCRP and bind to already dying CECs, which occurs early in disease pathogenesis, often before other disease symptoms are apparent. Once present, mCRP would likely amplify the existing inflammatory signaling. Whether mCRP initiates CEC loss or simply aids in damaged CEC removal remains to be investigated. Regardless of how or why it initially accumulates, mCRP seems to contribute to the inflammatory environment within the choriocapillaris before and during disease, which likely contributes to the development of AMD.

\section{Strategies to repair a diseased choroid}

Supported by our growing understanding of the genetics and pathophysiology in AMD, as well as advances in the fields of gene therapy and stem cell biology, many groups have focused on the development of novel strategies to halt or reverse AMD progression.

\section{Current therapies}

To help slow disease progression, patients with intermediate or advanced stages of AMD (both wet and dry) can take AREDS formulations, which have been shown to reduce the risk of progression by $25-30 \%$ over 5 years. ${ }^{102,103}$ The mechanism of action in AREDS vitamins includes both anti-oxidant and anti-inflammatory effects. ${ }^{56}$ Patients who develop CNV with exudate or blood leakage are typically given anti-VEGF injections to slow or reverse these symptoms. Although these are currently the only treatment options available, various ongoing clinical trials are being conducted to test new or repurposed therapeutic agents in AMD patients. Some of these agents include zimura (a PEGylated single-strand aptamer), which targets complement factor C5 in order to block its cleavage to become C5a and C5b, and MC-1101 (antihypertensive drug), which is suspected to increase choroidal blood flow, prevent BrM rupture, and decrease inflammation. Lampalizumab, an antibody targeted against complement factor $\mathrm{D}$, is a promising option for treatment of GA, as monthly intravitreal injections may reduce the 18-month growth rate of GA (reviewed by Danis et $a l^{104}$ ).

Numerous animal studies are also being conducted to test the efficacy of AMD therapies. Cashman et al assessed the treatment of laser-induced CNV in mice with adenovirus expressing the human soluble CD59 complement inhibitor protein. Subretinal injection of the vector was found to significantly protect against CNV formation and reduce MAC deposition at 7 days post laser, ${ }^{105}$ suggesting a potential utility for soluble CD59 in treating wet AMD. The use of fusion proteins to treat AMD is also an option currently being investigated. For example, tail vein injections of a CR2-fH fusion protein significantly reduces laser-induced CNV formation and helps preserve retinal function in mice 6 days post laser compared with PBS treatment. ${ }^{106}$ This list of studies is by no means complete, and as promising as these options may be for the treatment of AMD, much work to develop a safe and effective therapy in humans is still required. 


\section{Future therapies}

Although the development and use of anti-VEGF therapies have had immense success, the potential for subsequent development of GA in treated eyes remains a concern, as it has been estimated that up to one in every five patients treated with anti-VEGF injections will go on to develop GA. ${ }^{107}$ Therefore, understanding more about the key factors and molecular mechanisms involved in the progression of AMD to advanced stages is vital, not only to avoid the risk for anti-VEGF-induced loss of RPE cells and choriocapillaris, but more importantly to establish a plan to treat the disease before it progresses past the early stages.

\section{Cell replacement therapy with patient-specific iPSCs}

The lack of treatments available to halt the progression of AMD to advanced stages results in many patients with extensive cell and tissue loss within the macula. It is likely that cell replacement will be required to help patients such as these to regain any lost vision. As endothelial cells of the choriocapillaris are among the first cell type to become dysfunctional and are lost early in disease, and because of the vital role the choriocapillaris has in supporting the cells of the outer retina, recellularizing the choriocapillaris with healthy endothelial cells will likely be essential. To avoid immune-mediated donor cell rejection, which we expect to be a serious problem due to the robust expression of HLA class I molecules within the choriocapillaris (see section 3.3.1), use of autologous patient-derived cells would be ideal. The need to consider the risks of immune rejection is especially crucial for cell replacement therapy in AMD, which as described above, is caused in part by an insufficiently regulated immune system.

To date, we have been able to convincingly generate CECs from mouse fibroblast-derived iPSCs. ${ }^{108}$ The subsequent development of human patient-specific iPSCderived CECs will be a huge step forward. Specifically, in addition to being invaluable for evaluating disease pathophysiology, these cells will be essential for the development of an autologous CEC replacement strategy. That said, to restore vision in patients with severe GA, lost photoreceptor and RPE cells will also need to be replaced. As the inner retina is relatively spared in AMD, transplantation of healthy photoreceptor cells has the potential to restore vision, provided that synaptic connections can form between the transplanted photoreceptor cells and remaining host neurons. Although human iPSC-derived photoreceptor precursor cell transplantation with successful reintegration has been achieved in mice, ${ }^{109}$ many hurdles, including enhancement of post-transplant cellular survival and integration efficiency, remain. Of note, cell survival and integration can be greatly improved when donor cells are delivered on biomaterial cell support scaffolds. ${ }^{110}$

As discussed above, photoreceptor cells require CECs for their survival, but they also need support from healthy RPE cells. RPE cell transplantation studies have been performed first in mice, then in patients, for nearly 30 years. In the early patient trials, RPE cell suspensions were injected in the submacular space in an attempt to restore the RPE monolayer. From these studies, it was realized that RPE cells could not attach properly to a damaged or aged BrM, and more extensive transplantation methods would be required (reviewed by Alexander et $a^{111}$ ). For instance, a clinical trial using patient-derived iPSC-RPE cell sheets is currently in progress in Japan. In addition to cellular transplantation, a number of groups have successfully performed macular translocation studies using autologous RPE/BrM/ choroid grafts taken from the peripheral retina in patients with GA or excised CNV. Although it may sound like a promising option, this type of therapy requires the repositioning of healthy outer retina and choroid from another part of the patients own eye, resulting in a disruption to the patient's peripheral vision in addition to numerous complications. ${ }^{111}$

Altogether, patient-derived photoreceptor cells, RPE, and CECs have been successfully generated as individual therapeutic agents; however, the ability to assemble all three of these layers for transplantation is still required for patients with severe tissue loss. In order for these layers to remain apposed and properly oriented, the use of a safe, flexible, and biodegradable scaffold would be extremely beneficial. More work must be done to accomplish this complicated, yet necessary, triple-cell replacement strategy.

\section{Conclusion}

Age-related changes to BrM and the choroid may have a significant role in the development of AMD, as many of the changes observed in these tissues with age are even more dramatic in disease. Here, we have outlined the importance of the choroid (especially the choriocapillaris) in both health and disease. As the main source of oxygen and nutrients for the outer retina, the choriocapillaris is essential for the survival of the photoreceptor cells and RPE. The choriocapillaris, which is often overlooked with regard to $\mathrm{AMD}$, degenerates in early stages of disease, before loss of photoreceptor cells or RPE.

Why does CEC death occur? One reasonable possibility is that as the MAC accumulates in the aging choriocapillaris, and BrM loses its ability to bind the key regulatory factors (eg, CFH), the choriocapillaris becomes overwhelmed and is no longer able to properly control 
complement activation and protect itself from the deleterious effects of the MAC. This situation becomes even more dire when CFH carries loss-of-function mutations. Other factors, such as mCRP, may also accumulate in the choriocapillaris and $\mathrm{BrM}$ to exacerbate the inflammatory environment and accelerate complement-mediated damage to CECs. Once the choriocapillaris begins to degenerate, RPE and photoreceptor cells are at risk for their own dysfunction and degeneration. Photoreceptor cells appear especially sensitive to hypoxic insults, whereas the RPE monolayer can continue to survive even over an old avascular fibrotic scar. Furthermore, if RPE and photoreceptor cells are no longer receiving the nutrients and oxygen they require, they may provide signals for the remaining CECs to proliferate. Combining these events with (1) the observed loss of anti-angiogenic factors in BrM, (2) the addition of potent pro-angiogenic factors in the choriocapillaris (eg, MAC and mCRP), and (3) breaks in $\mathrm{BrM}$, these factors together may provide the perfect environment for CNV formation.

While our understanding of the risks and other contributing factors for AMD grows, devising mechanisms to halt or prevent these events is still a challenge. Owing to its vital roles in maintaining a healthy outer retina, the choroid must be taken into consideration during therapeutic development at all stages of disease. As we continue to make progress in our ability to defend and replace CECs, we get closer to saving and/or restoring vision in the millions of individuals living with AMD.

\section{Conflict of interest}

The authors declare no conflict of interest.

\section{Acknowledgements}

We thank the members of the Iowa Lions Eye Bank and the eye donors and their families who so generously support this research. This study was supported in part by NIH grants EY024605 and EY0026547, the Carver Chair in Ocular Cell Biology, and the Elmer and Sylvia Sramek Charitable Foundation.

\section{References}

1 Friedman DS, O'Colmain BJ, Muñoz B, Tomany SC, McCarty C, de Jong PTVM et al. Prevalence of age-related macular degeneration in the United States. Arch Ophthalmol 2004; 122(4): 564-572.

2 Wong WL, Su X, Li X, Cheung CMG, Klein R, Cheng C-Y et al. Global prevalence of age-related macular degeneration and disease burden projection for 2020 and 2040: a systematic review and meta-analysis. Lancet Global Health 2014; 2(2): 106-116.

3 Folk JC, Stone EM. Ranibizumab therapy for neovascular age-related macular degeneration. N Engl J Med 2010; 363(17): 1648-1655.

4 Wangsa-Wirawan ND, Linsenmeier RA. Retinal oxygen: fundamental and clinical aspects. Arch Ophthalmol 2003; 121(4): 547-557.

5 Feeney-Burns L, Burns RP, Gao C-L. Age-related macular changes in humans over 90 years old. Am J Ophthalmol 1990; 109(3): 265-278.

6 Curcio CA. Photoreceptor topography in ageing and age-related maculopathy. Eye 2001; 15(3): 376-383.

7 Owsley C, McGwin G, Clark ME, Jackson GR, Callahan MA, Kline LB et al. Delayed rod-mediated dark adaptation is a functional biomarker for incident early age-related macular degeneration. Ophthalmology 2016; 123(2): 344-351.

8 Bok D. The retinal pigment epithelium: a versatile partner in vision. J Cell Sci Suppl 1993; 17: 189-195.

9 Eldred GE, Katz ML. Fluorophores of the human retinal pigment epithelium: separation and spectral characterization. Exp Eye Res 1988; 47(1): 71-86.

10 Gao H, Hollyfield JG. Aging of the human retina. Differential loss of neurons and retinal pigment epithelial cells. Invest Ophthalmol Vis Sci 1992; 33(1): 1-17.

11 Curcio CA, Johnson M, Rudolf M, Huang JD. The oil spill in ageing Bruch membrane. Br J Ophthalmol 2011; 95(12): 1638-1645.

12 Nakaizumi Y, Hogan MJ, Feeney L. The ultrastructure of Bruch's membrane. 3. The macular area of the human eye. Arch Ophthalmol 1964; 72: 395-400.

13 Bhutto I, Lutty G. Understanding age-related macular degeneration (AMD): relationships between the photoreceptor/retinal pigment epithelium/Bruch's membrane/choriocapillaris complex. Mol Aspects Med 2012; 33(4): 295-317.

14 Bhutto IA, Uno K, Merges C, Zhang L, McLeod DS, Lutty GA. Reduction of endogenous angiogenesis inhibitors in Bruch's membrane of the submacular region in eyes with age-related macular degeneration. Arch Ophthalmol 2008; 126(5): 670-678.

15 Del Priore LV, Geng L, Tezel TH, Kaplan HJ. Extracellular matrix ligands promote RPE attachment to inner Bruch's membrane. Curr Eye Res 2002; 25(2): 79-89.

16 Friedman DS, Katz J, Bressler NM, Rahmani B, Tielsch JM. Racial differences in the prevalence of age-related macular degeneration. Ophthalmology 1999; 106(6): 1049-1055.

17 Lambert NG, ElShelmani H, Singh MK, Mansergh FC, Wride MA, Padilla M et al. Risk factors and biomarkers of age-related macular degeneration. Prog Retin Eye Res 2016; 54: 64-102.

18 Thornton J, Edwards R, Mitchell P, Harrison RA, Buchan I, Kelly SP. Smoking and age-related macular degeneration: a review of association. Eye 2005; 19(9): 935-944.

19 Shahid H, Khan JC, Cipriani V, Sepp T, Matharu BK, Bunce C et al. Age-related macular degeneration: the importance of family history as a risk factor. Br J Ophthalmol 2012; 96(3): 427-431.

20 Haines JL, Hauser MA, Schmidt S, Scott WK, Olson LM, Gallins $\mathrm{P}$ et al. Complement factor $\mathrm{H}$ variant increases the risk of age-related macular degeneration. Science 2005; 308 (5720): 419-421.

21 Edwards AO, Ritter R, Abel KJ, Manning A, Panhuysen C, Farrer LA. Complement factor H polymorphism and agerelated macular degeneration. Science 2005; 308(5720): 421-424. 
22 Klein RJ, Zeiss C, Chew EY, Tsai J-Y, Sackler RS, Haynes C et al. Complement factor $\mathrm{H}$ polymorphism in age-related macular degeneration. Science 2005; 308(5720): 385-389.

23 Hageman GS, Anderson DH, Johnson LV, Hancox LS, Taiber AJ, Hardisty LI et al. A common haplotype in the complement regulatory gene factor $\mathrm{H}(\mathrm{HF} 1 / \mathrm{CFH})$ predisposes individuals to age-related macular degeneration. Proc Natl Acad Sci USA 2005; 102(20): 7227-7232.

24 Gold B, Merriam JE, Zernant J, Hancox LS, Taiber AJ, Gehrs $\mathrm{K}$ et al. Variation in factor B (BF) and complement component 2 (C2) genes is associated with age-related macular degeneration. Nat Genet 2006; 38(4): 458-462.

25 Maller JB, Fagerness JA, Reynolds RC, Neale BM, Daly MJ, Seddon JM. Variation in complement factor 3 is associated with risk of age-related macular degeneration. Nat Genet 2007; 39: 1200-1201.

26 Yates JRW, Sepp T, Matharu BK, Khan JC, Thurlby DA, Shahid $\mathrm{H}$ et al. Complement $\mathrm{C} 3$ variant and the risk of age-related macular degeneration. N Engl J Med 2007; 357(6): 553-561.

27 Wang Q, Zhao H-S, Li L. Association between complement factor I gene polymorphisms and the risk of age-related macular degeneration: a meta-analysis of literature. Int $J$ of Ophthalmol 2016; 9(2): 298-305.

28 Khandhadia S, Cipriani V, Yates JRW, Lotery AJ. Age-related macular degeneration and the complement system. Immunobiology 2012; 217(2): 127-146.

29 Fritsche LG, Loenhardt T, Janssen A, Fisher SA, Rivera A, Keilhauer $\mathrm{CN}$ et al. Age-related macular degeneration is associated with an unstable ARMS2 (LOC387715) mRNA. Nat Genet 2008; 40(7): 892-896.

30 Davis MD, Gangnon RE, Lee L-Y, Hubbard LD, Klein BEK, Klein R et al. The Age-Related Eye Disease Study severity scale for age-related macular degeneration: AREDS Report No. 17. Arch Ophthalmol 2005; 123(11): 1484-1498.

31 Sarks SH, Arnold JJ, Killingsworth MC, Sarks JP. Early drusen formation in the normal and aging eye and their relation to age related maculopathy: a clinicopathological study. Br J Ophthalmol 1999; 83(3): 358-368.

32 Lengyel I, Tufail A, Hosaini Al H, Luthert P, Bird AC, Jeffery G. Association of drusen deposition with choroidal intercapillary pillars in the aging human eye. Invest Ophthalmol Vis Sci 2004; 45(9): 2886-2892.

33 Berenberg TL, Metelitsina TI, Madow B, Dai Y, Ying G-S, Dupont JC et al. The association between drusen extent and foveolar choroidal blood flow in age-related macular degeneration. Retina 2012; 32(1): 25-31.

34 Mullins RF, Johnson MN, Faidley EA, Skeie JM, Huang J. Choriocapillaris vascular dropout related to density of drusen in human eyes with early age-related macular degeneration. Invest Ophthalmol Vis Sci 2011; 52(3): 1606-1612.

35 Curcio CA, Millican CL. Basal linear deposit and large drusen are specific for early age-related maculopathy. Arch Ophthalmol 1999; 117(3): 329-339.

36 Sarks J, Arnold J, Ho I-V, Sarks S, Killingsworth M. Evolution of reticular pseudodrusen. Br J Ophthalmol 2011; 95(7): 979-985.

37 Curcio CA, Messinger JD, Sloan KR, McGwin G, Medeiros NE, Spaide RF. Subretinal drusenoid deposits in non-neovascular age-related macular degeneration: morphology, prevalence, topography, and biogenesis model. Retina 2013; 33(2): 265-276.
38 Alten F, Clemens CR, Heiduschka P, Eter N. Localized reticular pseudodrusen and their topographic relation to choroidal watershed zones and changes in choroidal volumes RPD and choroidal watershed zones. Invest Ophthalmol Vis Sci 2013; 54(5): 3250-3257.

39 Corvi F, Souied EH, Capuano V, Costanzo E, Benatti L, Querques $\mathrm{L}$ et al. Choroidal structure in eyes with drusen and reticular pseudodrusen determined by binarisation of optical coherence tomographic images. Br J Ophthalmol; e-pub ahead of print 17 May 2016; doi:10.1136/ bjophthalmol-2016-308548.

40 Thorell MR, Goldhardt R, Nunes RP, de Amorim Garcia Filho CA, Abbey AM, Kuriyan AE et al. Association between subfoveal choroidal thickness, reticular pseudodrusen, and geographic atrophy in agerelated macular degeneration. Ophthalmic Surg Lasers Imaging Retina 2015; 46(5): 513-521.

41 Kutoglu T, Yalcin B, Kocabiyik N, Ozan H. Vortex veins: anatomic investigations on human eyes. Clin Anat 2005; 18 (4): 269-273.

42 Scholfield CN, McGeown JG, Curtis TM. Cellular physiology of retinal and choroidal arteriolar smooth muscle cells. Microcirculation 2007; 14(1): 11-24.

43 Wallman J, Wildsoet C, Xu A, Gottlieb MD, Nickla DL, Marran L et al. Moving the retina: choroidal modulation of refractive state. Vision Res 1995; 35(1): 37-50.

44 Hasegawa T, McLeod DS, Bhutto IA, Prow T, Merges CA, Grebe $\mathrm{R}$ et al. The embryonic human choriocapillaris develops by hemo-vasculogenesis. Dev Dyn 2007; 236(8): 2089-2100.

45 Baba T, Grebe R, Hasegawa T, Bhutto I, Merges C, McLeod DS et al. Maturation of the fetal human choriocapillaris. Invest Ophthalmol Vis Sci 2009; 50(7): 3503-3509.

46 Lutty GA, Hasegawa T, Baba T, Grebe R, Bhutto I, McLeod DS. Development of the human choriocapillaris. Eye 2010; 24(3): 408-415.

47 Abi-Hanna D, Wakefield D, Watkins S. HLA antigens in ocular tissues: I. in vivo expression in human eyes. Transplantation 1988; 45(3): 610.

48 Bakker M, Grumet FC, Feltkamp T, Kijlstra A. HLA-antigens in the human uvea. Document Ophthalmol 1986; 61: 271-279.

49 Goverdhan SV, Howell MW, Mullins RF, Osmond C, Hodgkins PR, Self J et al. Association of HLA class I and class II polymorphisms with age-related macular degeneration. Invest Ophthalmol Vis Sci 2005; 46(5): 1726-1729.

50 Jordan SC, Choi J, Kim I, Vo A, Peng A, Kahwaji J. Risk factors associated with the development of histocompatibility leukocyte antigen sensitization. Curr Opin Organ Transplant 2016; 21(4): 447-452.

51 McLeod DS, Lefer DJ, Merges C, Lutty GA. Enhanced expression of intracellular adhesion molecule- 1 and P-selectin in the diabetic human retina and choroid. Am J Pathol 1995; 147(3): 642-653.

52 Mullins RF, Skeie JM, Malone EA, Kuehn MH. Macular and peripheral distribution of ICAM-1 in the human choriocapillaris and retina. Mol Vis 2006; 12: 224-235.

53 Shen WY, Yu MJT, Barry CJ, Constable IJ, Rakoczy PE. Expression of cell adhesion molecules and vascular endothelial growth factor in experimental choroidal neovascularisation in the rat. Br J Ophthalmol 1998; 82(9): 1063-1071.

54 Sakurai E, Taguchi H, Anand A, Ambati BK, Gragoudas ES, Miller JW et al. Targeted disruption of the CD18 or ICAM-1 
gene inhibits choroidal neovascularization. Invest Ophthalmol Vis Sci 2003; 44(6): 2743-2747.

55 Skeie JM, Fingert JH, Russell SR, Stone EM, Mullins RF. Complement component C5a activates ICAM-1 expression on human choroidal endothelial cells. Invest Ophthalmol Vis Sci 2010; 51(10): 5336-5342.

56 Zeng S, Hernández J, Mullins RF. Effects of antioxidant components of AREDS vitamins and zinc ions on endothelial cell activation: implications for macular degeneration. Invest Ophthalmol Vis Sci 2012; 53(2): 1041-1047.

57 Hageman GS, Zhu XL, Waheed A, Sly WS. Localization of carbonic anhydrase IV in a specific capillary bed of the human eye. Proc Natl Acad Sci USA 1991; 88(7): 2716-2720.

58 Yang Z, Alvarez BV, Chakarova C, Jiang L, Karan G, Frederick JM et al. Mutant carbonic anhydrase 4 impairs $\mathrm{pH}$ regulation and causes retinal photoreceptor degeneration. Hum Mol Genet 2005; 14(2): 255-265.

59 Fukushima I, McLeod DS, Lutty GA. Intrachoroidal microvascular abnormality: a previously unrecognized form of choroidal neovascularization. Am J Ophthalmol 1997; 124(4): 473-487.

60 Yuan X, Gu X, Crabb JS, Yue X, Shadrach K, Hollyfield JG et al. Quantitative proteomics: comparison of the macular Bruch membrane/choroid complex from age-related macular degeneration and normal eyes. Mol Cell Proteomics 2010; 9(6): 1031-1046.

61 Godfrey WA. Characterization of the choroidal mast cell. Trans Am Ophthalmol Soc 1987; 85: 557.

62 May CA. Mast cell heterogeneity in the human uvea. Histochemistry 1999; 112(5): 381-386.

63 Bhutto IA, McLeod DS, Jing T, Sunness JS, Seddon JM, Lutty GA. Increased choroidal mast cells and their degranulation in age-related macular degeneration. Br J Ophthalmol 2016; 100(5): 720-726.

64 Stein M-P, Mold C, Clos Du TW. C-reactive protein binding to murine leukocytes requires f $\gamma$ receptors. J Immunol 2000; 164(3): 1514-1520.

65 Nazarov PG, Pronina AP. The influence of cholinergic agents on histamine release from HMC-1 human mast cell line stimulated with IgG, C-reactive protein and compound 48/80. Life Sci 2012; 91(21-22): 1053-1057.

66 Cherepanoff S, McMenamin P, Gillies MC, Kettle E, Sarks SH. Bruch's membrane and choroidal macrophages in early and advanced age-related macular degeneration. Br J Ophthalmol 2010; 94(7): 918-925.

67 Wang JCC, Cao S, Wang A, To E, Law G, Gao J et al. $\mathrm{CFH} Y 402 \mathrm{H}$ polymorphism is associated with elevated vitreal GM-CSF and choroidal macrophages in the postmortem human eye. Mol Vis 2015; 21: 264-272.

68 Skeie JM, Mullins RF. Macrophages in neovascular age-related macular degeneration: friends or foes? Eye 2009; 23(4): 747-755.

69 Nickla DL, Wallman J. The multifunctional choroid. Prog Retin Eye Res 2010; 29(2): 144-168.

70 Arora KS, Jefferys JL, Maul EA, Quigley HA. Choroidal thickness change after water drinking is greater in angle closure than in open angle eyeswater drinking test. Invest Ophthalmol Vis Sci 2012; 53(10): 6393-6402.

71 Kim DY, Silverman RH, Chan RVP, Khanifar AA, Rondeau M, Lloyd $\mathrm{H}$ et al. Measurement of choroidal perfusion and thickness following systemic sildenafil (Viagra). Acta Ophthalmol 2013; 91(2): 183-188.
72 Wakatsuki Y, Shinojima A, Kawamura A, Yuzawa M. Correlation of aging and segmental choroidal thickness measurement using swept source optical coherence tomography in healthy eyes. PLoS ONE 2015; 10(12): e0144156.

73 Keenan TDL, Pickford CE, Holley RJ, Clark SJ, Lin W, Dowsey AW et al. Age-dependent changes in heparan sulfate in human Bruch's membrane: implications for age-related macular degenerationheparan sulfate in human Bruch's membrane. Invest Ophthalmol Vis Sci 2014; 55(8): 5370-5379.

74 Chen M, Glenn JV, Dasari S, McVicar C, Ward M, Colhoun $\mathrm{L}$ et al. RAGE regulates immune cell infiltration and angiogenesis in choroidal neovascularization. PLOS ONE 2014; 9(2): e89548.

75 Grunwald JE, Metelitsina TI, Dupont JC, Ying G-S, Maguire MG. Reduced foveolar choroidal blood flow in eyes with increasing AMD severity. Invest Ophthalmol Vis Sci 2005; 46(3): 1033-1038.

76 Sohn EH, Khanna A, Tucker BA, Abràmoff MD, Stone EM, Mullins RF. Structural and biochemical analyses of choroidal thickness in human donor eyesanalyses of choroidal thickness in human donor eyes. Invest Ophthalmol Vis Sci 2014; 55(3): 1352-1360.

77 Whitmore SS, Braun TA, Skeie JM, Haas CM, Sohn EH, Stone EM et al. Altered gene expression in dry age-related macular degeneration suggests early loss of choroidal endothelial cells. Mol Vis 2013; 19: 2274-2297.

78 Rudolf M, Curcio CA. Esterified cholesterol is highly localized to Bruch's membrane, as revealed by lipid histochemistry in wholemounts of human choroid. J Histochem Cytochem 2009; 57(8): 731-739.

79 Nilsson B, Nilsson Ekdahl K. The tick-over theory revisited: is C3 a contact-activated protein? Immunobiology 2012; 217 (11): 1106-1110.

80 Chen M, Forrester JV, Xu H. Synthesis of complement factor $\mathrm{H}$ by retinal pigment epithelial cells is down-regulated by oxidized photoreceptor outer segments. Exp Eye Res 2007; 84(4): 635-645.

81 Ji S-R, Wu Y, Potempa LA, Liang Y-H, Zhao J. Effect of modified C-reactive protein on complement activation A possible complement regulatory role of modified or monomeric C-reactive protein in atherosclerotic lesions. Arterioscler Thromb Vasc Biol 2006; 26(4): 935-941.

82 Gershov D, Kim S, Brot N, Elkon KB. C-reactive protein binds to apoptotic cells, protects the cells from assembly of the terminal complement components, and sustains an antiinflammatory innate immune response implications for systemic autoimmunity. J Exp Med 2000; 192(9): 1353-1364.

83 Makou E, Herbert AP, Barlow PN. Functional anatomy of complement factor H. Biochemistry 2013; 52(23): 3949-3962.

84 Mullins RF, Dewald AD, Streb LM, Wang K, Kuehn MH, Stone EM. Elevated membrane attack complex in human choroid with high risk complement factor H genotypes. Exp Eye Res 2011; 93(4): 565-567.

85 Seth A, Cui J, To E, Kwee M, Matsubara J. Complementassociated deposits in the human retina. Invest Ophthalmol Vis Sci 2008; 49(2): 743-750.

86 Mullins RF, Schoo DP, Sohn EH, Flamme-Wiese MJ, Workamelahu G, Johnston RM et al. The membrane attack complex in aging human choriocapillaris: relationship to macular degeneration and choroidal thinning. Am J Pathol 2014; 184(11): 3142-3153. 
87 Chirco KR, Tucker BA, Stone EM, Mullins RF. Selective accumulation of the complement membrane attack complex in aging choriocapillaris. Exp Eye Res 2015; 146: 393-397.

88 Zeng S, Whitmore SS, Sohn EH, Riker MJ, Wiley LA, Scheetz TE et al. Molecular response of chorioretinal endothelial cells to complement injury: implications for macular degeneration. J Pathol 2016; 238: 446-456.

89 Rhodes B, Fürnrohr BG, Vyse TJ. C-reactive protein in rheumatology: biology and genetics. Nat Rev Rheumatol 2011; 7(5): 282-289.

90 Eisenhardt SU, Habersberger J, Murphy A, Chen Y-C, Woollard KJ, Bassler N et al. Dissociation of pentameric to monomeric C-reactive protein on activated platelets localizes inflammation to atherosclerotic plaques. Circ Res 2009; 105(2): 128-137.

91 Lauer N, Mihlan M, Hartmann A, Schlötzer-Schrehardt U, Keilhauer C, Scholl HPN et al. Complement regulation at necrotic cell lesions is impaired by the age-related macular degeneration-associated factor-H His402 risk variant. J Immunol 2011; 187(8): 4374-4383.

92 Perkins SJ, Okemefuna AI, Nan R. Unravelling protein-protein interactions between complement factor $\mathrm{H}$ and C-reactive protein using a multidisciplinary strategy. Biochem Soc Trans 2010; 38(4): 894-900.

93 Pasceri V, Willerson JT, Yeh ET. Direct proinflammatory effect of C-reactive protein on human endothelial cells. Circulation 2000; 102(18): 2165-2168.

94 Molins B, Fuentes-Prior P, Adán A, Antón R, Arostegui JI, Yagüe $\mathrm{J}$ et al. Complement factor $\mathrm{H}$ binding of monomeric C-reactive protein downregulates proinflammatory activity and is impaired with at risk polymorphic $\mathrm{CFH}$ variants. Sci Rep 2016; 6: 22889.

95 Chirco KR, Whitmore SS, Wang K, Potempa LA, Halder JA, Stone EM et al. Monomeric C-reactive protein and inflammation in Age-related Macular Degeneration. J Pathol 2016; 240(2): 173-183.

96 Seddon JM, Gensler G, Milton RC, Klein ML, Rifai N. Association between C-reactive protein and age-related macular degeneration. JAMA 2004; 291(6): 704-710.

97 Seddon JM, George S, Rosner B, Rifai N. Progression of age-related macular degeneration: prospective assessment of C-reactive protein, interleukin 6, and other cardiovascular biomarkers. Arch Ophthalmol 2005; 123(6): 774-782.

98 Seddon JM, Gensler G, Rosner B. C-reactive protein and $\mathrm{CFH}, \mathrm{ARMS} 2 / \mathrm{HTRA} 1$ gene variants are independently associated with risk of macular degeneration. Ophthalmology 2010; 117(8): 1560-1566.

99 Robman L, Baird PN, Dimitrov PN, Richardson AJ, Guymer RH. C-reactive protein levels and complement factor $\mathrm{H}$ polymorphism interaction in age-related macular degeneration and its progression. Ophthalmology 2010; 117 (10): 1982-1988.
100 Johnson PT, Betts KE, Radeke MJ, Hageman GS, Anderson DH, Johnson LV. Individuals homozygous for the age-related macular degeneration risk-conferring variant of complement factor $\mathrm{H}$ have elevated levels of CRP in the choroid. Proc Natl Acad Sci USA 2006; 103(46): 17456-17461.

101 Bhutto IA, Baba T, Merges C, Juriasinghani V, McLeod DS, Lutty GA. C-reactive protein and complement factor $\mathrm{H}$ in aged human eyes and eyes with age-related macular degeneration. Br J Ophthalmol 2011; 95(9): 1323-1330.

102 Age-Related Eye Disease Study Research Group. A randomized, placebo-controlled, clinical trial of high-dose supplementation with vitamins $C$ and $E$, beta carotene, and zinc for age-related macular degeneration and vision loss: AREDS report no. 8. Arch Ophthalmol 2001; 119(10):1417-1436.

103 Chew EY, Clemons TE, SanGiovanni JP, Danis R, Ferris FL, Elman $\mathrm{M}$ et al. Lutein+zeaxanthin and omega-3 fatty acids for age-related macular degeneration. J Am Med Assoc 2013; 309(19): 2005-2015.

104 Danis RP, Lavine JA, Domalpally A. Geographic atrophy in patients with advanced dry age-related macular degeneration: current challenges and future prospects. Clin Ophthalmol 2015; 9: 2159-2174.

105 Cashman SM, Ramo K, Kumar-Singh R. A non membrane-targeted human soluble CD59 Attenuates choroidal neovascularization in a model of age related macular degeneration. PLOS ONE 2011; 6(4): e19078.

106 Rohrer B, Long Q, Coughlin B, Renner B, Huang Y, Kunchithapautham $\mathrm{K}$ et al. A targeted inhibitor of the complement alternative pathway reduces RPE injury and angiogenesis in models of age-related macular degeneration. Adv Exp Med Biol 2010; 703: 137-149.

107 Grunwald JE, Daniel E, Huang J, Ying G-S, Maguire MG, Toth CA et al. Risk of geographic atrophy in the comparison of age-related macular degeneration treatments trials. Ophthalmology 2014; 121(1): 150-161.

108 Songstad AE, Wiley LA, Duong K, Kaalberg E, Flamme-Wiese MJ, Cranston CM et al. Generating iPSC-derived choroidal endothelial cells to study age-related macular degenerationiPSC-derived choroidal endothelial cells. Invest Ophthalmol Vis Sci 2015; 56(13): 8258-8267.

109 Tucker BA, Mullins RF, Streb LM, Anfinson K, Eyestone ME, Kaalberg E et al. Patient-specific iPSC-derived photoreceptor precursor cells as a means to investigate retinitis pigmentosa. Elife 2013; 2: e00824.

110 Tomita M, Lavik E, Klassen H, Zahir T, Langer R, Young MJ. Biodegradable polymer composite grafts promote the survival and differentiation of retinal progenitor cells. Stem Cells 2005; 23(10): 1579-1588.

111 Alexander P, Thomson H, Luff AJ, Lotery AJ. Retinal pigment epithelium transplantation: concepts, challenges, and future prospects. Eye 2015; 29(8): 992-1002. 